\title{
Ischemic neuropathy and rhabdomyolysis as presenting symptoms of postpartum cardiomyopathy
}

\author{
Rick C. G. Helmich · Hanneke W. M. van Laarhoven • \\ Hennie C. Schoonderwaldt • Mirian C. H. Janssen
}

Published online: 26 June 2008

(C) The Author(s) 2008

\begin{abstract}
Rhabdomyolysis and peripheral neuropathy are two distinct disease entities which are rarely encountered in combination. We present a woman with rhabdomyolysis and peripheral neuropathy 3 weeks postpartum. Her symptoms were caused by bilateral femoral artery thrombosis due to postpartum cardiomyopathy (PPCM). This demonstrates that PPCM may present with predominantly non-cardial symptoms and underscores the importance of rapidly recognizing this disorder.
\end{abstract}

Keywords Postpartum cardiomyopathy · Neuropathy · Rhabdomyolysis

\section{Case report}

A 22-year-old woman was referred from another hospital to our department of neurology because of severe rhabdomyolysis (CK levels of $>13,000 \mathrm{U} / \mathrm{l}$ ) and muscle weakness of both legs. Five days before admission she suffered from acute muscle cramps, followed by muscle weakness in both legs and numbness of both feet. Her medical history revealed preeclampsia 1 month earlier and she delivered a

R. C. G. Helmich · H. C. Schoonderwaldt

Department of Neurology, Radboud University Nijmegen

Medical Centre, Nijmegen, The Netherlands

H. W. M. van Laarhoven - M. C. H. Janssen

Department of Internal Medicine, Radboud University Nijmegen

Medical Centre, Nijmegen, The Netherlands

H. W. M. van Laarhoven ( $₫)$

Department of Medical Oncology 452, Radboud University

Nijmegen Medical Centre, PO Box 9101, 6500 HB Nijmegen,

The Netherlands

e-mail: h.vanlaarhoven@onco.umcn.nl healthy baby 3 weeks before presentation. She used folic acid and ferrofumarate because of the recent pregnancy and nitrofurantoine because of a urinary tract infection. She did not smoke and used no alcohol. Neurological examination revealed a paresis of the anterior tibial and extensor hallucis longus muscles on both sides (left $>$ right). There was sock-shaped hyposensibility without pain. Both feet were warm and had a normal color. The right leg was edematous and arterial pulsations were absent in the right foot. Electromyography showed multiple neuropathies in distal branches of the left peroneal, posterior tibial, sural and superficial peroneal nerves. Muscle biopsy revealed no abnormalities. On angiography of the legs thrombosis of the right internal iliac artery, the right proximal superficial femoral artery (AFS), the left AFS, popliteal and anterior tibial arteries was observed as well as an infarction of the right kidney (Fig. 1). The chest X-ray showed a widened mediastinum and echocardiography revealed a decreased left ventricular function (ejection fraction 30\%). No thrombophilic risk factors were found and there was no evidence for an autoimmune disease (normal levels of homocysteine, antithrombin, protein $\mathrm{C}$ and $\mathrm{S}$, factor $\mathrm{V}$ mutation, prothrombin mutation, lupus anticoagulant, anticardiolipin, ANA, ANCA, complement $\mathrm{C} 3$ and $\mathrm{C} 4$ all negative). Based on a cardiomyopathy in the context of her recent pregnancy, postpartum cardiomyopathy (PPCM) was diagnosed. Later, when asked for earlier symptoms of cardiomyopathy, the patient mentioned that she had been progressively dyspnoeic in the last weeks of her pregnancy. Thrombectomy of the occluded arteries was performed and anticoagulation (low molecular weight heparin) was started. Thereafter the patient was treated with a vitamin $\mathrm{K}$ antagonist, acetylsalicylic acid and an ace-inhibitor. After 8 months the patient had only mild neuropathic pain in her left foot, which responded well to gabapentin. Her heart 


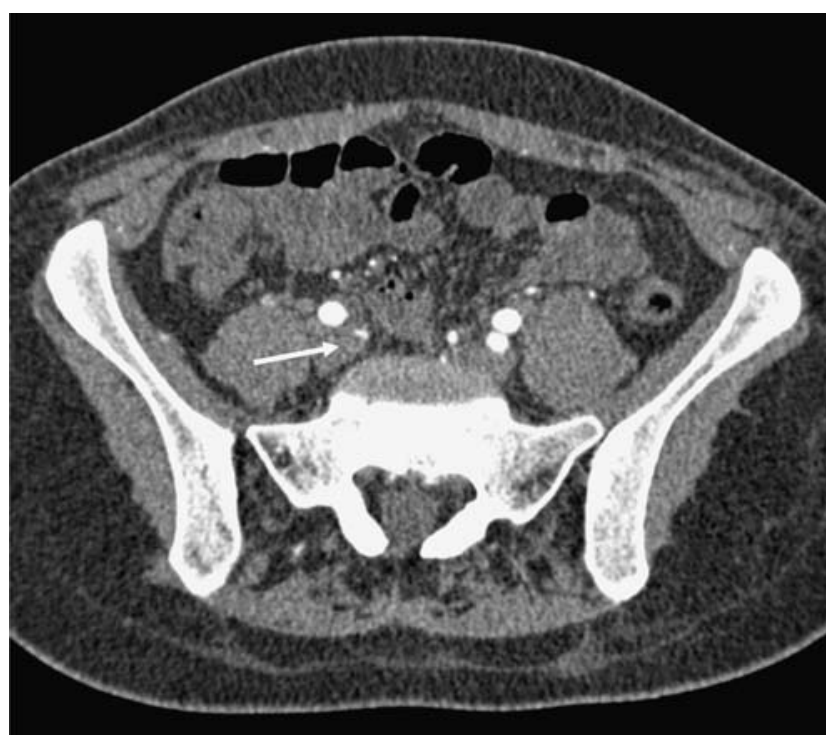

Fig. 1 CT angiography of the patient showing a thrombus in the right iliac artery (indicated with the arrow)

function had normalized almost completely (left ventricle ejection fraction of 52\%). There were no signs of peripheral vascular disease.

\section{Discussion}

Our patient presented with symptoms and signs of rhabdomyolysis and peripheral neuropathy. These two distinct disease entities are rarely encountered in combination. In our case rhabdomyolysis and peripheral neuropathy were attributed to one common cause, namely ischaemia due to acute arterial thromboembolism as a complication of PPCM [1]. This diagnosis was delayed because the cardiovascular symptoms were not immediately recognized.

Cardiovascular disease is rare in women of childbearing age. In the general population arterial thrombosis is most commonly caused by atherosclerosis. However, in young women other mechanisms may play a role, especially in the absence of multiple risk factors for atherosclerosis like a family history of (premature) atherosclerosis, smoking, diabetes mellitus and obesity [2]. First a status of hypercoaguability should be considered, for example due to the antiphospholipid syndrome or hyperhomocysteinaemia [3, 4]. The relation between arterial thrombosis and the heritable thrombophilias factor $\mathrm{V}$ Leiden mutation, prothrombin G20210A mutation, protein C deficiency, protein $\mathrm{S}$ deficiency, and antithrombin deficiency are less well established [5]. Also pregnancy induces a state of hypercoaguability, due to the fact that most clotting factors increase during pregnancy and fibrinolytic activity is decreased [6]. Although pregnancy by itself usually does not lead to (arterial) thrombosis, the concurrence of pregnancy with other risk factors for thromboembolism can disclose serious cardiovascular disease [7].

Arterial thromboembolic events in young patients may also occur due to structural abnormalities of the heart [2]. Prosthetic heart valves or valvular heart disease as a result of congenital abnormalities or rheumatic heart disease are most common. In young patients also a patent foramen ovale should be considered leading to a so-called paradoxical embolus which originates from the venous circulation [8]. Finally, intracardiac thrombosis due to atrial fibrillation or severe dysfunction of a ventricle as a result of cardiomyopathy may be the origin of arterial thromboembolism. In fact, the latter was the case in our patient.

Our patient meet the criteria for PPCM as set forth by Demakis [1]. PPCM is observed in 1 of 3,000-4,000 live births [9] and mortality is approximately $15 \%$ despite optimal treatment [10]. Preeclampsia is a known risk factor for PPCM [10]. Patients most commonly present with signs and symptoms of systolic heart disease, but with (unnoticed) progression of the disease the heart may dilate and thrombus formation in the ventricles may occur. Neurological symptoms can arise in case of cerebral embolization [11], but also thromboembolism in the lower extremities has been described [12]. Therefore, as is also demonstrated in our case, PPCM may present with predominantly noncardial symptoms.

In conclusion, the unusual combination of rhabdomyolysis and peripheral neuropathy in a patient should urge on doctors to look for a common vascular cause. The early recognition of arterial thromboembolism as a result of PPCM may prevent further morbidity and mortality of this disease.

Open Access This article is distributed under the terms of the Creative Commons Attribution Noncommercial License which permits any noncommercial use, distribution, and reproduction in any medium, provided the original author(s) and source are credited.

\section{References}

1. Demakis JG, Rahimtoola SH, Sutton GC, Meadows WR, Szanto PB, Tobin JR et al (1971) Natural course of peripartum cardiomyopathy. Circulation 44:1053-1061

2. Walker ID (2003) Arterial thromboembolism in pregnancy. Best Pract Res Clin Haematol 16:297-310. doi:10.1016/S1521-6926 (02)00100-7

3. Branch W, Eller AG (2006) Antiphospholipid syndrome and thrombosis. Clin Obstet Gynecol 49:861-874. doi:10.1097/01. grf.0000211955.61121.3b

4. Christen WG, Ajani UA, Glynn RJ, Hennekens CH (2000) Blood levels of homocysteine and increased risks of cardiovascular disease: causal or casual? Arch Intern Med 160:422-434. doi: 10.1001/archinte.160.4.422 
5. Boekholdt SM, Kramer MH (2007) Arterial thrombosis and the role of thrombophilia. Semin Thromb Hemost 33:588-596. doi: 10.1055/s-2007-985755

6. Clark P, Brennand J, Conkie JA, McCall F, Greer IA, Walker ID (1998) Activated protein C sensitivity, protein C, protein $S$ and coagulation in normal pregnancy. Thromb Haemost 79:11661170

7. Kaaja RJ, Greer IA (2005) Manifestations of chronic disease during pregnancy. JAMA 294:2751-2757. doi:10.1001/jama. 294.21.2751

8. Di TM, Sacco RL, Gopal A, Mohr JP, Homma S (1992) Patent foramen ovale as a risk factor for cryptogenic stroke. Ann Intern Med 117:461-465
9. Pearson GD, Veille JC, Rahimtoola S, Hsia J, Oakley CM, Hosenpud JD et al (2000) Peripartum cardiomyopathy: National Heart, Lung, and Blood Institute and Office of Rare Diseases (National Institutes of Health) workshop recommendations and review. JAMA 283:1183-1188. doi:10.1001/jama.283.9.1183

10. Sliwa K, Fett J, Elkayam U (2006) Peripartum cardiomyopathy. Lancet 368:687-693. doi:10.1016/S0140-6736(06)69253-2

11. Hodgman MT, Pessin MS, Homans DC, Panis W, Prager RJ, Lathi ES et al (1982) Cerebral embolism as the initial manifestation of peripartum cardiomyopathy. Neurology 32:668-671

12. Gagne PJ, Newman JB, Muhs BE (2003) Ischemia due to peripartum cardiomyopathy threatening loss of a leg. Cardiol Young 13:209-211. doi:10.1017/S1047951103000416 